\title{
Comparison of Knowledge Regarding Leucorrhoea Among Women in Selected Urban and Rural Area
}

\author{
Archana S. Teltumbde ${ }^{1}$, Prachi Choudhari ${ }^{2}$, Airin David ${ }^{3}$, \\ Bhagyashri Dhenge ${ }^{4}$, Sonal Dhobe ${ }^{5}$ and Shubham Dhole ${ }^{6}$ \\ ${ }^{2-6}$ Students, Smt. Radhikabai Meghe Memorial College of Nursing, Datta Meghe Institute of \\ Medical Sciences, (Deemed to be University) Sawangi Meghe, Wardha, Maharashtra, India
}

\section{ABSTRACT}

Introduction: Leucorrhoea, vaginal discharge is a universal problem of all women, it is a condition of persistent and excessive vaginal discharge.Vaginal discharge is a common complaint, among women in Asia.Female genitals are very much prone to infections since they are moist, more sweaty and covered. Women may complaint of a clear white or mucoid discharge other prior to menses or at mild cycles. This is catarrhal discharge from the mucus membrane of the female genital tract. It is commonly known as white discharge Aim: To comparison the knowledge regarding leucorrhoea among women in selected urban and rural area.Materials and Methods: Objectives of the Study1.To assess the existing knowledge of leucorrhoea among general women in urban area.2.To assess the existing knowledge of leucorrhoea among general women in rural area3.To compare knowledge regarding leucorrhoea among urban and rural area.. Assumptions1. Urban and rural women may have some knowledge regarding leucorrhoea2.Urban and rural women may have some interest to know leucorrhea. Variables -Demographic variables - Age, Religion, Education, Marital status, dietary pattern, family type and parity-Research variable - Knowledge among women regarding leucorrhoea Sample Size:Sample size consist of 100 women between 18-40 years of age residing in selected urban and rural area. Sampling Technique Convenient sampling technique was used to select the sample for the present study. Inclusion Criteria for the sampling 1 .Women of 18-40 years who are willing to participate2. Women available during data collection3. Women who are able to read and write in Marathi Exclusion criteria for sampling1. Women who are critically ill2. Health personnel 3.Women who attended similar workshop Method of Data Collection The structured questionnaire was used to collect the data required for the study. Result: The study was conducted among women residing in selected urban and rural area in order to compare knowledge regarding leucorrhea. After the completion of study it has been revealed that women residing in urban area has more knowledge as compare to women residing in rural area. In this study, in comparison of urban women the mean sore was 10.96 and in comparison of rural women the mean score was 8.6 respectively. Also mean percentage of knowledge score of urban and rural women was $21.96 \%$ and $17.25 \%$ respectively. The calculated ' $t$ ' value was 1.978 . The calculated 't' value was much higher than the tabulated value at $5 \%$ level of significance which is statistically acceptable level of significance. In addition the calculated ' $p$ ' value for knowledge score regarding leucorrhea was $0.05(\geq 0.05)$.

\section{KEY WORDS: LEUCORRHOEA, VAGINAL DISCHARGE, WOMEN.}

\section{ARTICLE INFORMATION}

${ }^{*}$ Corresponding author email: ladearchu@gmail.com Received 11th Oct 2020 Accepted after revision 28th Dec 2020 Print ISSN: 0974-6455 Online ISSN: 2321-4007 CODEN: BBRCBA

Thomson Reuters ISI Web of Science Clarivate Analytics USA and Crossref Indexed Journal

\section{Clarivate
Analytics}

NAAS Journal Score 2020 (4.31)

A Society of Science and Nature Publication, Bhopal India 2020. All rights reserved.

Online Contents Available at: http//www.bbrc.in/

Doi: http://dx.doi.org/10.21786/bbrc/13.15/40

\section{INTRODUCTION}

Leucorrhoea, vaginal discharge is a universal problem of all women, it is a condition of persistent and excessive vaginal discharge 1.Vaginal discharge is a common complaint, among women in Asia.2 Female genitals are very much prone to infections since they are moist, more sweaty and covered. Women may complaint of a clear white or mucoid discharge other prior to

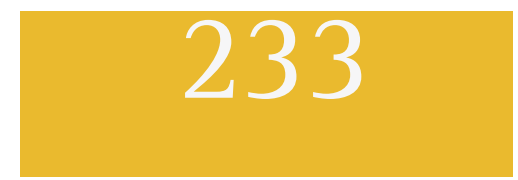


menses or at mild cycles. This is catarrhal discharge from the mucus membrane of the female genital tract. It is commonly known as white discharge. It may be due to any specific pathology or due to poor health Et unhygienic condition of the female genital organ. Such discharges may originate from vagina ,ovaries, fallopian tubes or most probably the cervix. It represents desquamation of vaginal epithelial cells because of effects of estrogen on vaginal mucosa. Vaginal discharges may be physiological or pathological. In physiological discharge normal vaginal flora[lactobacilli] colonizes the vaginal epithelium and may have a role in defense against infection. They maintain the vaginal normal ph between 3.8 to 4.4 .Although abnormal vaginal discharge often prompts women to seek screening for sexually transmitted infections.

\section{MATERIAL AND METHODS}

A Descriptive research design was used in the study. The study was conducted during January 2018 and the setting was selected in the rural and urban area of wardha after getting ethical permission Ethical clearance letter (IEC letter no. Ref. no: DMIMS(DU)/IEC/201718/70462019-20/436). The sample size was calculated to include 100 respondents. Objectives Of The Study1. To assess the existing knowledge of leucorrhoea among general women in urban area.2. To assess the existing knowledge of leucorrhoea among general women in rural area3. To compare knowledge regarding leucorrhoea among urban and rural area.4. To find the association between knowledge regarding leucorrhoea with selected demographic variables.

Assumptions1. Urban and rural women may have some knowledge regarding leucorrhoea2. Urban and rural women may have some interest to know leucorrhea. Variables -Demographic variables - Age, Religion, Education, Marital status, dietary pattern, family type and parity-Research variable-Knowledge among women regarding leucorrhoea Sample Size: Sample size consist of 100 women between 18-40 years of age residing in selected urban and rural area. Sampling Technique Convenient sampling technique was used to select the sample for the present study. Inclusion Criteria for the sampling 1 .Women of 18-40 years who are willing to participate2. Women available during data collection3. Women who are able to read and write in MarathiExclusion criteria for sampling 1. Women who are critically ill2. Health personnel3. Women who attended similar workshop Method Of Data Collection The structured questionnaire was used to collect the data required for the study.

\section{Major Findings of the Study Organization of Findings}

The data was coded and analysed as per objectives under following headings:

\footnotetext{
Section I: Distribution of women according to their demographic variable.

Section II: A] Assessment of the knowledge of women
}

residing in urban area

\section{B] Assessment of the knowledge of women residing in rural area}

Section III: Comparison of the knowledge score of women residing in urban and rural area.

\section{Section I}

\section{Distribution of Sample According to their Demographic Variable}

- Distribution of urban women according to their age in years shows that $6(12 \%)$, of them belongs to age group 18-22 years, 20(40\%), of them belongs to age group 23-27 years, $9(18 \%)$ of them belongs to age group 28-32 years whereas $15(30 \%)$ belongs to 32 years and above. Distribution of rural women according to their age in years shows that $6(12 \%)$, of them belongs to age group 18-22 years, $18(36 \%)$, of them belongs to age group 23-27 years, $7(14 \%)$ of them belongs to age group 28-32 years whereas $19(38 \%)$ belongs to 32 years and above respectively.

- Distribution of urban women according to religion shows that $40(80 \%)$, of them belongs to hindu religion, 9(18\%), of them belongs to Buddhist religion, $1(2 \%)$ of them belongs to Muslim religion whereas none were of other religion. Distribution of rural women according to religion shows that $46(92 \%)$, of them belongs to hindu religion, 2(4\%), of them belongs to Buddhist religion, 2(4\%), of them belongs to Muslim religion whereas none were of other religion respectively

- Distribution of urban women according to dietary pattern shows that 31(62\%), of them were vegetarian, whereas $19(38 \%)$ of them were non-vegetarian. Distribution of rural women according to dietary pattern shows that $46(92 \%)$, of them were vegetarian, whereas $4(8 \%)$ of them were non-vegetarian respectively.

- Distribution of urban women according to education shows that $2(4 \%)$, of them has completed primary education, 27(54\%), of them has completed secondary education 21(42\%), of them has completed graduation, whereas none has done other. Distribution of rural women according to education shows that $10(20 \%)$, of them has completed primary education, 30(60\%), of them has completed secondary education $10(20 \%)$, of them has completed graduation, whereas none has done other respectively.

- Distribution of urban women according to family type shows that 32(64\%), of them belongs to nuclear family, whereas $18(36 \%)$ of them belongs to joint family. Distribution of rural women according to family type shows that 24(48\%), of them belongs to nuclear family, whereas $26(52 \%)$ of them belongs to joint family respectively.

- Distribution of urban women according to marital status shows that $46(92 \%)$, of them were married, whereas $4(8 \%)$ of them were unmarried. Distribution of rural women according to marital status shows that $42(84 \%)$ of them were married, and $8(16 \%)$ of 
women were unmarried .

- Distribution of urban women according to parity shows that 22(44\%), of them has a single child, $21(42 \%)$, of them had two child $4(8 \%)$, of them had three and more child whereas $3(6 \%)$ had none. Distribution of rural women according to parity shows that 13(26\%), of them has a single child,
$28(56 \%)$, of them had two child $4(8 \%)$, of them had three and more child whereas $5(10 \%)$ had none respectively.

\section{Section II}

A] Assessment of the Knowledge of Women Residing in Urban Area

\begin{tabular}{|c|c|c|c|c|}
\hline Level of knowledge score & Score range & Percentage score & Frequency & Percentage \\
\hline Very Poor & $0-4$ & $0-20 \%$ & 1 & $2 \%$ \\
\hline Poor & $5-8$ & $21-40 \%$ & 10 & $20 \%$ \\
\hline Average & $9-12$ & $41-60 \%$ & 23 & $46 \%$ \\
\hline Good & $13-16$ & $61-80 \%$ & 13 & $26 \%$ \\
\hline Excellent & $17-20$ & $81-100 \%$ & 3 & $6 \%$ \\
\hline Minimum score & 4 & & & \\
\hline Maximum score & 19 & & & \\
\hline Mean score & 10.96 & & & \\
\hline Mean \% & $21.92 \%$ & & & \\
\hline
\end{tabular}

Table no.1 shows frequency and percentage wise distribution of urban women according to level of knowledge regarding leucorrhea. The level of knowledge were seen in 5 categories- very poor, poor, average, good and excellent. In which $1(2 \%)$, of women were very poor, $10(20 \%)$, women were poor, 23(46\%), of women were average, $13(26 \%)$, of women were were good and 3(6\%) of them were excellent. The minimum score was 4 and maximum was 19 , the mean score was 10.96 and mean percentage was $21.96 \%$.

\section{B] Assessment of the Knowledge of Women Residing in Rural Area}

Figure 1: Level of knowledge score in urban area

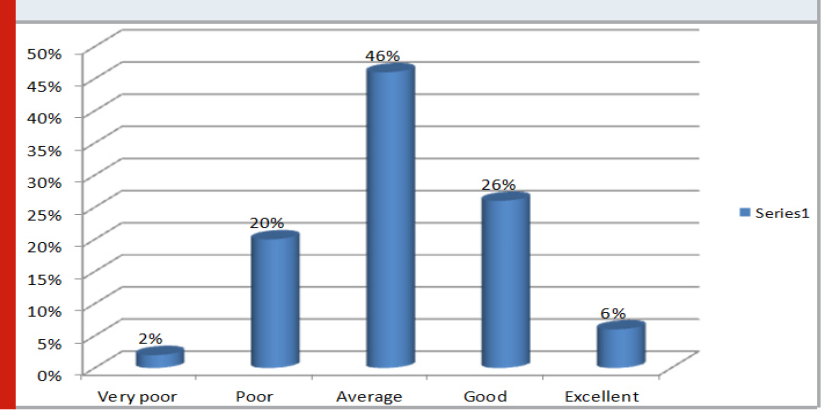

Table 2. Assessment of the knowledge of women residing in rural area

\begin{tabular}{|l|c|c|c|c|}
\hline Level of knowledge score & Score range & Percentage score & Frequency & Percentage \\
\hline Very Poor & $0-4$ & $0-20 \%$ & 3 & $6 \%$ \\
\hline Poor & $5-8$ & $21-40 \%$ & 23 & $46 \%$ \\
\hline Average & $9-12$ & $41-60 \%$ & 16 & $32 \%$ \\
\hline Good & $13-16$ & $61-80 \%$ & 7 & $14 \%$ \\
Excellent & $17-20$ & $81-100 \%$ & 1 & $2 \%$ \\
\hline Minimum score & 2 & & & \\
\hline Maximum score & 15 & & & \\
\hline Mean score & 8.6 & & & \\
\hline Mean \% & $17.2 \%$ & & & \\
\hline
\end{tabular}

Table no.2 shows frequency and percentage wise distribution of rural women according to level of knowledge regarding leucorrhea. The level of knowledge were seen in 5 categories- very poor, poor, average, good and excellent. In which 3(6\%), of women were very poor,
23(46\%), women were poor, 16(32\%), of women were average, $7(14 \%)$, of women were were good and $1(2 \%)$ of them were excellent. The minimum score was 2 and maximum was 15 , the mean score was 8.6 and mean percentage was $17.2 \%$. 
Figure 2: Level of knowledge score in rural area

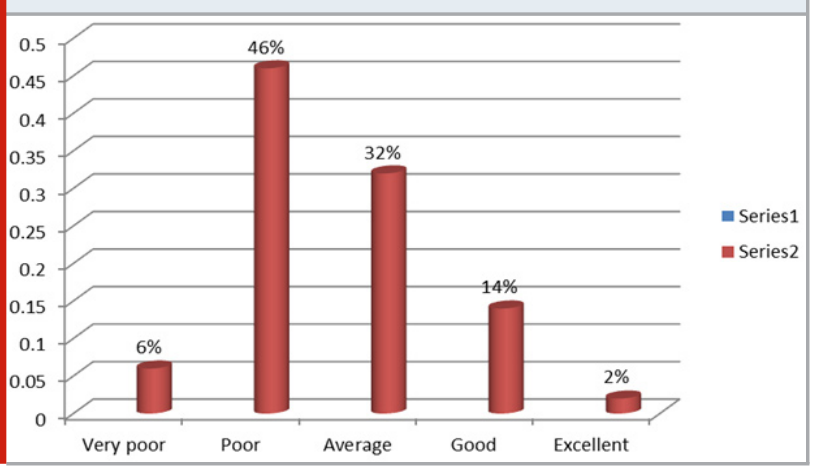

Section III

Comparison of the Knowledge Score of Women Residing
Figure 3: Assessment with Knowledge Score of urban and rural area

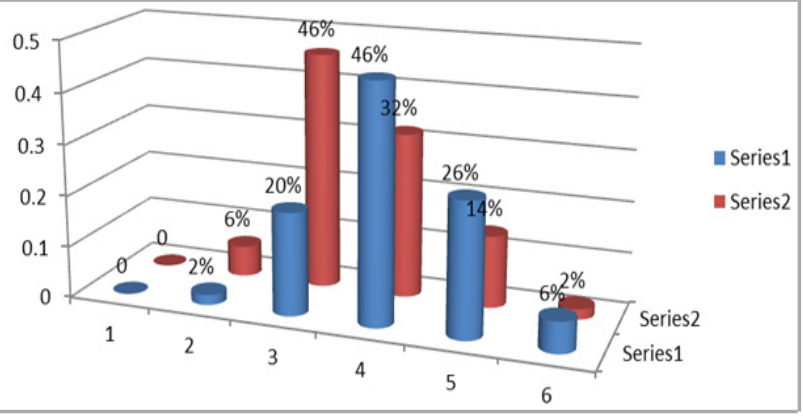

in Urban And Rural Area

Table 3. Comparison of the knowledge score of women residing in urban and rural area

Level of
$\begin{aligned} & \text { knowledge score } \\ & \text { Very Poor }\end{aligned}$

\begin{tabular}{|l|l|c|c|c|}
\hline Area & $\begin{array}{l}\text { Mean } \\
\text { score }\end{array}$ & $\begin{array}{c}\text { Calculated } \\
\text { 't' value }\end{array}$ & df & 'p' value \\
\hline Urban area & 10.96 & 1.978 & 50 & .053 \\
\hline NS, $p>0.05$ & & & & \\
\hline
\end{tabular}

\section{CONCLUSION}

The study was conducted among women residing in selected urban and rural area in order to compare knowledge regarding leucorrhea. After the completion of study it has been revealed that women residing in urban area has more knowledge as compare to women residing in rural area. In this study, in comparison of urban women the mean sore was 10.96 and in comparison of rural women the mean score was 8.6 respectively. Also mean percentage of knowledge score of urban and rural women was $21.96 \%$ and $17.25 \%$ respectively. The calculated 't' value was 1.978. The calculated ' $t$ ' value was much higher than the tabulated value at 5\% level of significance which is statistically acceptable level of significance. In addition the calculated ' $p$ ' value for knowledge score regarding leucorrhea was 0.05 $(\geq 0.05)$.
Figure 4: Comparison of knowledge of women residing in urban and rural area

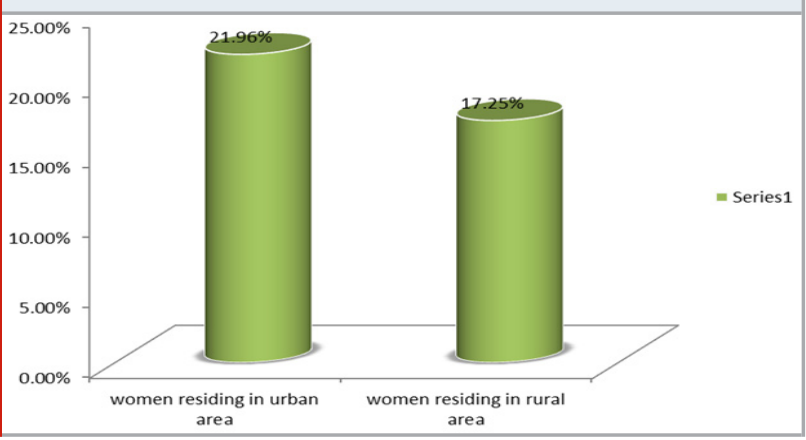

\section{DISCUSSION}

Findings of the study revealed that study subject has poor knowledge regarding leucorrhea. The finding of the study are consisted with various previous studies .In this study the knowledge is compared with the variable such as Age ,Religion, Education, Dietary pattern, Marital status, Family type, Parity .However the subject who have now knowledge or higher education has shown significance compared to those who have less education. The study 
has a limitation that the sample was drawn from a local urban area, which may show certain variation as the characteristics of people residing in city area may differ. Further more as it was a continental study the collected were relatively brief and concise.

The findings also shows that the knowledge score is not associated with demographic variables hypothesis, is assumed that this may be due to unavailability of women of various demographic variable components A community based study was conducted among rural North Indian women, in three selected road side villages of Panchkula, Haryana. A total of 236 married women of 15 - 45 years were identified by a hose to house survey and were interviewed by a Female Health Worker on various aspects of vaginal discharge. The prevalence of leucorrhoea was identified as $28.7 \%$, and among them the consultation rate was 59\%. A cross-sectional study was conducted in rural areas in the district of Sirmour, Himachal Pradesh. 452 married women of reproductive age group i.e of 15-44 years in villages under Primary Health Centre, Sarahan were identified by using simple random sampling method and were interviewed. This study shows the higher prevalence of leucorrhoea and it is 51 .

\section{Conflicts of interest: Nil}

Financial support: Self

\section{REFERENCES}

Abraham E. rakoff, M.D, P. Brooke bland, MD, Leukorrhea : clinical and therapeutic aspect , J Am Med Assoc (1940);115(12):1013-1018

Beryl West, Bernice Nayak . Why do women complain of vaginal discharge.A population survey of infectious and psychosocial risk factors in a South Asian Community, Int. J. Epidemioly 2005;34(4):853

Chongyunliu, O.M.D, L.Ac., Yong Deng, O.M.D, with Andrew Mcintyre, L.Ac, Encyclopedia of Chinese and U.S patent herbal medicines, McGraw Hill Professional, 01-Jul-1999,Illustrated edition

Female population India.[online]2010[cited 21st Aug,2010. Available from:http//wikigender.org/index. php/women_andmen_india_2010.

Huffman JW, Principles of adolescent gynecology, Obstet Gynecol Annu(1975);4:287-308

Henry Edward Iehn, Iridology : The diagnosis of eye , edition 6th , Kessinger publishing ,01-Aug-2003

Hoyme, UB 1989 Bacterial Vaginosis Zentralblattfur Gynakologie ,111:1589-1598

Santosh SK. Chaturvedi, Phycasthenic syndrome related to leucorrhea in Indian women, Journal of psychosomatic Obstetrics and Gynecology (1988); 8: 67-72

Statistics of reproductive tract infections. karnataka: [online] Available from:http//cmdr_dharwad_rht.org. Trollope Kumar K Cultural and biomedical meanings of the complaints of leucorrhea in South Asian Women Tropical Medicine and International Health (2001), 6: 260-266 